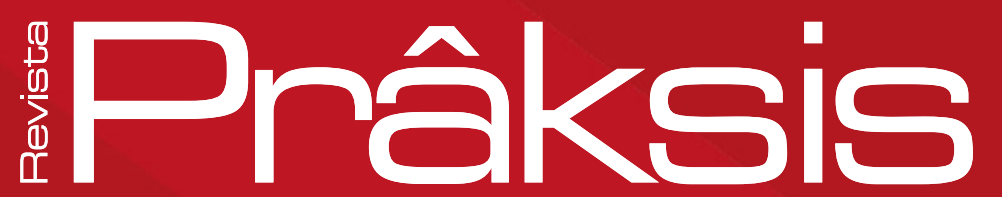

Recebido em: 22 de julho de 2017

Aprovado em: 23 de outubro de 2017

Sistema de Avaliação: Double Blind Review

RPR |a. 15| n. 1 | p. 121-138|jan./jun. 2018

DOI: https://doi.org/10.25112/rpr.v1i0.1308

\title{
A SAUDADE DOS SABORES \\ E O COMÉRCIO ÉTNICO DOS IMIGRANTES ITALIANOS NO BRASIL (1875-1914)
}

THE NOSTALGIA OF THE FLAVORS AND

THE ETHNIC BUSINESS OF THE ITALIANS

IMMIGRANTS IN BRAZIL (1875-1914)

\section{Antonio de Ruggiero}

Doutor em Studi storici per l'età moderna e contemporânea pela Università degli

Studi di Firenze (Firenze/Itália). Professor na Pontifícia Universidade Católica do Rio

Grande do Sul (Porto Alegre/Brasil). E-mail: antonio.deruggiero@gmail.com. 


\section{RESUMO}

Nos anos da Grande Imigração (1875-1914), muitos italianos abriram, nas principais cidades brasileiras que os acolheram, atividades comerciais no setor da alimentação. Como escreveu o jornalista Francesco Bianco depois de uma passagem no país sul-americano em 1922, "os italianos conseguiram impor a sua culinária, assumindo o domínio do paladar destes povos". O objetivo deste artigo é analisar os aspectos distintivos do comércio étnico de gêneros alimentícios importados, que favoreceram um fenômeno de mercado induzido e permitiram a muitos italianos abrir suas próprias casas de despachos nos principais centros urbanos do país. Em particular, é enfatizado o caso de São Paulo, onde a grande quantidade de peninsulares presentes propiciou o surgimento de inúmeros empreendimentos de caráter étnico. Através de uma análise qualitativa de documentos variados como correspondências familiares, imprensa étnica e, principalmente, almanaques raros relativos aos numerosos grupos de italianos instalados no Brasil, se reflete sobre o tema da alimentação como um dos principais elementos na definição de identidades étnicas e, consequentemente, como nova possibilidade para empreendimentos comerciais nas cidades de imigração.

Palavras-chave: Imigração italiana. Comércio étnico. Enogastronomia. Identidade étnica

\section{ABSTRACT}

In the years of the Great Immigration (1875-1914), many Italians opened, in the most important cities of Brazil, commercial activities in the food segment. As the journalist Francesco Bianco wrote during his trip to the South-American country, "the Italians manage to impose their culinary, taking over the domain of people's taste". The objective of the present article is to analyze the distinctive features of the ethnic business of exchanged food products, which favored a phenomenon named "induced business" and allowed many Italians to open their own dispatch houses in the main urban centers in the country. In particular, it is emphasized the case of São Paulo, where the large amount of immigrants provide the advent of numerous ethnic enterprises. Through a qualitative analysis of varied documents such as family correspondence, ethnic press and, especially, rare almanacs related to the numerous groups of Italians living in Brazil, this article shows the theme of food as one of the main elements in the definition of ethnic identities and, consequently, as a new possibility for commercial enterprises in the cities of immigration. Keywords: Italian immigration. Ethnic business. Wine and gastronomy. Ethnic Identity. 


\section{INTRODUÇÃO}

Dois anos atrás, a "Esposizione Universale Milano 2015", focalizada na grande questão da alimentação mundial em tempos de globalização, evidenciou, entre os seus temas principais, o conceito da importância da comida e das culturas gastronômicas como elementos distintivos e simbólicos fortes na definição das identidades coletivas - "étnicas", poder-se-ia dizer, quando nos referimos às temáticas imigratórias, como será feito neste breve texto. De fato, a culinária italiana, também no Brasil, um país com quase 30 milhões de descendentes italianos, representou, por diversas gerações até hoje, um traço essencial da etnicidade, tanto dos primeiros imigrantes, como dos seus descendentes. Existem muitos estudos interessantes que analisam a questão da relação entre comida e emigração em termos gerais, tanto do ponto de vista antropológico quanto daquele histórico-social, a partir das reflexões de Paola Corti (1998), Peppino Ortoleva (1992), Piero Bevilacqua (1981), Ernesto Di Renzo (2015), Fabio Caffarena (2006), Vito Teti (2001), somente para citar alguns autores italianos de referência.

Muitas fontes históricas relativas à emigração italiana no Brasil tratam a respeito desse fenômeno. Pelo presente trabalho, ressalta-se a importância das correspondências privadas dos imigrantes, considerando que o assunto da comida se liga diretamente a uma dimensão emotiva íntima e familiar. Foi justamente a partir de uma nostalgia dos sabores de casa, continuamente evocada nessas cartas, que muitos imigrantes nos primeiros anos da grande imigração italiana, investiram dinheiro em atividades comerciais de importação que podiam propiciar a parcial manutenção de costumes e tradições gastronômicas originárias.

O artigo, concentra-se mais especificamente sobre os aspectos distintivos do comércio de gêneros alimentícios "étnicos" importados, que permitiu a muitos italianos abrir "casas de despachos" e revendas, no período dos grandes êxodos de massa no Brasil. No centro de várias cidades brasileiras de acolhimento, alguns deles conseguiram ascender economicamente, graças à demanda contínua de produtos originários da península, incrementada pelos intensos fluxos migratórios. Fontes indispensáveis utilizadas para abordar este tema se revelaram os periódicos em língua italiana que, a partir do final do século XIX circulavam nas principais cidades brasileiras, relatando sobre a organização social das coletividades italianas e suas atividades empresariais propagandeadas abundantemente. Ainda mais úteis resultaram alguns almanaques comerciais étnicos, exemplares raros que nos fornecem um quadro bastante exaustivo relativamente às trajetórias migratórias de empresários peninsulares que souberam aproveitar as condições favoráveis de inserção neste segmento de mercado. 


\section{A SAUDADE DOS SABORES}

Em uma interessante análise sobre as correspondências privadas que alguns lígures imigrados para a América do Sul trocavam com os parentes que permaneceram na Itália no período da "Grande Emigração" (1875-1914), Fabio Caffarena (2006) destacou a saudade dos "sabores de casa" e a ligação indissolúvel com as tradições alimentares das suas origens como um tema habitual e bastante assíduo. No caso específico brasileiro, embora muitas cartas provenientes das regiões coloniais italianas enfatizassem voluntariamente os aspectos positivos ligados à abundância "americana" nos consumos e a uma dieta cotidiana que se beneficiava de alimentos por vezes raros nos campos italianos - como a carne -, a questão da nostalgia gastronômica é fortemente presente. Inúmeros autores utilizaram apropriadamente as descrições sugestivas e eficazes de Edmondo De Amicis, que registrou a frequente propensão dos imigrantes italianos a desafiar os controles das alfândegas portuárias para trazer consigo na viagem seus produtos enogastronômicos, com a intenção de presentear os parentes que os esperavam do outro lado do oceano:

Era comovente escutar que se tratava de coisas sem valor, na maioria das vezes de presentes, que levavam para parentes ou amigos da América: alguns levavam uma garrafa de vinho especial; outros, um queijo caciocavallo; outros ainda, um salame ou um quilo de massa de Genova ou de Nápoles; um litro de azeite, uma caixa de figos secos, até um punhado de feijões, mas daquele cultivado em casa, daquele cantinho da horta que o amigo ou o parente certamente devia se lembrar (DE AMICIS, 2017, p. 250).

A nostalgia dos sabores perdidos é uma presença fixa nas cartas de vários imigrantes ítalo-brasileiros, mesmo entre aqueles que não se arrependeram da escolha de emigrar, mas que continuavam a evocar os prazeres da convivência e da genuinidade das comidas deixadas no paese. Trata-se de memórias subjetivas que - como evidencia Vito Teti (2001, p. 588) - remetiam, sobretudo, "à cozinha festiva, aromática, com milhares de sabores, perfumes e cores, ao universo de elos e de afetos" dos mesmos migrantes. Giuseppe Luti, emigrado de Fosciandora, nos arredores de Lucca, nos primeiros anos do século passado havia construído uma discreta fortuna como "fabricante e comerciante de cervejas e bebidas" em um pequeno município do interior do estado de São Paulo; mas nas cartas expedidas à esposa evocava os sabores longínquos abandonados:

Não podes crer como eu teria vontade de voltar para a Itália para beber aquele bom vinho, para saborear aquela boa e apetitosa polenta que tantas vezes recordei embora aqui se coma sempre a carne e galinhas; mas penso que eu chegando lá deverei 
trabalhar a terra e morrer trabalhando para manter minha família, coisa que já não sou mais acostumado a fazer? ${ }^{1}$.

A mesma coisa acontecia com Amedeo Lucchesi, imigrante e proprietário de um próspero segmento comercial no estado paulista, que manifestava aos parentes a profunda nostalgia pelos afetos das pessoas caras deixadas na sua pátria; mas também pela "polenta com o porco fresco", a qual, saboreada na sua Garfagnana, possuía todo um outro gosto².

Muitos outros exemplos, em suma, comprovam as considerações daqueles autores que, como Caffarena, enxergaram nos sabores de casa dos emigrantes, uma significativa herança cultural que agia intimamente para manter vivas a lembrança e a ligação com o território de origem. Ao mesmo tempo, torna-se necessária para amenizar a inexorável dificuldade da integração em uma realidade completamente nova: "receber e consumir produtos que chegavam da Itália como azeite, castanhas, queijos, cogumelos, azeitonas e vinho permite reatar o vínculo com a comunidade de origem, e estancar a hemorragia da identidade subjetiva e social" (CAFFARENA, 2006, p. 2) presente nos lugares de acolhimento.

Também acredita-se que, desde sempre, os italianos apresentaram maior dificuldade de adaptação na esfera culinária, manifestando no exterior formas de resistências que aparecem mais tenazes em comparação aos demais processos de melting pot. Nas primeiras gerações de imigrantes ítalo-brasileiros isto resultou bastante evidente, tanto que muitos compatriotas conseguiram construir discretas fortunas econômicas aproveitando desta necessidade; isso já antes que começassem também no Brasil os processos de desenvolvimento industrial, que inevitavelmente proporcionaram nos anos sucessivos o nascimento de pioneiras fábricas alimentícias "italianas", no sentido de uma produção de alimentos de "tipo italiano".

Sempre se reconheceu o papel dos italianos como difusores de modelos e de costumes gastronômicos típicos da própria cultura alimentar, que se beneficiou, aliás, de uma grande riqueza de tradições diferenciadas entre as diversas regiões e territórios, historicamente impregnados de influências e sobreposições externas greco-romanas, árabes, espanholas, francesas etc. (DALL'OGLIO, 1993).

Como assinalava o jornalista Francesco Bianco (1922, p. 188), após uma visita ao país sul-americano, nestes lugares os italianos teriam quase monopolizado o comércio de gêneros alimentares e com os seus saberes na cozinha conseguiram "impor a própria culinária, assumindo o domínio dos gostos

\footnotetext{
${ }^{1}$ Arquivo da Fundação Paolo Cresci (Lucca), Carta, coll. 1260, "Avaré 25.6.1912".

2 Arquivo da Fundação Paolo Cresci (Lucca), Carta, coll. 3055, "15 febbraio 1910".
} 
daqueles povos". Embevecidos de retórica patriótica, as suas observações almejavam analisar as grandes vantagens econômicas que o fenômeno propiciava, até mesmo para as finanças da pátria-mãe:

De outra parte, existem aqui milhões de compatriotas que comem com certeza de uma maneira bastante italiana. E os filhos desses italianos, os quais algumas vezes esquecem a pátria de seus pais, nunca se esquecem das cozinhas das suas mães... É um fenômeno de importância colossal, que pode fazer rir apenas aos ingênuos; e que há, mais do que não se sabe, uma transcendência moral de primeira ordem. De todas as formas, esta bagatela culinária revertia para a Itália a cada ano centenas e centenas de milhões de liras em ouro (BIANCO, 1992, p.188).

Além dos exageros, é uma evidência que, mesmo do ponto de vista linguístico, diversas palavras relativas à gastronomia no Brasil foram tomadas - frequentemente com alguma adaptação - diretamente do italiano, e fazem parte hoje do vocabulário português-brasileiro (MARCATO, 2010).

\section{COMIDAS TRANSNACIONAIS}

No caso brasileiro, na verdade, os estudos sempre se concentraram com maior atenção sobre o caráter preponderantemente agrícola da imigração, que foi direcionada essencialmente às colônias rurais do Sul, e nas fazendas do Sudeste sucessivamente. Neste sentido, são numerosas as pesquisas referentes à contribuição e formação de uma cultura alimentar híbrida, definida como "colonial", que perpetuava, por meio da utilização de produtos locais, as tradições gastronômicas de origem. Estas eram ligadas, por exemplo, ao cultivo das vinhas e das oliveiras, ao preparo da polenta e do pão, à produção de embutidos etc. Poder-se-ia falar de um Know How culinário italiano que se integra - "transnacionaliza-se", se diria hoje - para se adaptar rapidamente às condições que o território local poderia oferecer ${ }^{3}$.

Mas também nesse caso, não se pode esquecer que o verdadeiro made in Italy fez o seu ingresso com força até mesmo nos ambientes rurais, sem a necessidade de alfândegas ou de escritórios de importação, mas graças aos mesmos colonos que, como no caso do Rio Grande do Sul - explica Flavia Cristaldi (2015) em uma recente publicação -, transportavam dentro das próprias malas nas travessias transoceânicas os brotos das vinhas italianas conservados até mesmo dentro das batatas para manter o grau de umidade necessário para conservá-los e plantá-los nas novas terras. Na verdade, a assim chamada

\footnotetext{
${ }^{3}$ Algumas pesquisas histórico-antropológicas mais recentes no Estado do Rio Grande do Sul podem ser consideradas exemplares na renovação do interesse relativo à função identitária da alimentação nas colônias agrícolas italianas do Estado mais meridional do Brasil: Miriam Oliveira Santos, Maria Catarina Zanini (2008); Rosana Peccini (2011); Franciele Bandeira Figueiredo (2009).
} 
Região Colonial Italiana do Rio Grande do Sul foi marcada desde o início do século XIX por experimentos precursores no plantio de vinhas italianas, que se intensificaram com a chegada das primeiras levas de imigrantes protagonistas do processo de colonização planejada a partir de 1875 para o povoamento de inteiras regiões até então desabitadas (PELLANDA, 1950, p. 42). E junto com os brotos das vinhas chegaram também as primeiras oliveiras italianas, importadas em Caxias do Sul em 1882 por Giuseppe Boff, seguido por Annuccio Ungaretti alguns anos mais tarde. A mesma coisa ocorreu com as plantas frutíferas, e é o caso de recordar o nome de Giuseppe Eberle, que em 1884 transportou consigo da Itália numerosas plantinhas de macieira, pereira, cerejeira, castanheira e amendoeira, que deram origem a um dos mais importantes pomares da região (CINQUANTENARIO, 2000, p. 224-225).

Apesar destes episódios, porém, como evidenciaram muitos analistas desde os tempos contemporâneos à grande imigração italiana no Brasil, o caráter prevalentemente agrícola desta mobilidade humana havia obstaculizado, em um certo sentido, a penetração direta de produtos alimentares italianos no mercado local. Os esforços do governo, principalmente a partir do período de Francesco Crispi (1887-1889), para promover um maior comércio entre Itália e Brasil e favorecer por meio dos imigrantes - considerados "os mais fiéis consumidores das mercadorias da pátria-mãe" (FRANCESCHINI, 1908, p. 957) - aquela forma de "mercado induzido" tão desejada para melhorar as finanças gerais do Estado (VERNASSA, 1996), não foram suficientes para contrastar a supremacia de países como a Inglaterra, a França e a Alemanha, que no Brasil estabeleceram desde muito tempo as próprias bases comerciais, embora não existisse a seu favor uma imigração de seus compatriotas (IL BRASILE E GLI ITALIANI, 1906). Na ausência de acordos comerciais efetivos, que se concretizaram somente em 1950, as relações de importações e exportação entre o Brasil e a Itália não foram intensas como poderiam ser, considerando o grande potencial numérico, assim como a influência social dos imigrantes. Dada a falta de um fluxo regular de importações, os italianos radicados no Novo Mundo iniciaram rapidamente a substituir os produtos do seu país de origem, com alimentos locais confeccionados, porém seguindo o "uso italiano" (FRAGMENTOS DA PRESENÇA ITALIANA NO BRASIL, 2002). Apesar dos dados estatísticos gerais colocarem a Itália nas últimas posições para exportações de gêneros alimentícios, deve-se considerar que, ao menos no período dos grandes fluxos em direção ao Brasil, isso não aconteceu naquelas cidades onde se concentrava uma abundante imigração paralela às atividades agrícolas4.

\footnotetext{
${ }^{4}$ Como pesquisador da história da emigração italiana no Brasil, já há alguns anos, acompanhando um projeto dirigido pela estudiosa ítalo-brasileira Núncia Santoro de Constantino junto a Pontifícia Universidade Católica do Rio Grande do Sul, concentrei a minha atenção acerca dos contextos urbanos do país. Considerando, de fato, o grande peso que a imigração agrícola teve no Brasil, os estudos sobre as repercussões que os processos imigratórios italianos tiveram nas cidades menores, são ainda poucos e fragmentados.
} 


\section{O COMERCIO ÉTNICO DE ALIMENTOS}

Nossas pesquisas ainda incipientes referem-se propriamente aos principais centros urbanos brasileiros que, no período da "grande emigração" (1875-1914), acolheram italianos que se ocuparam em atividades comerciais no setor alimentício de importação direta da Itália. Neste caso, a comida tornou-se um verdadeiro e próprio business que fez a fortuna de muitos investidores, fossem eles pequenos ou grandes.

Seguindo os passos de um estudo exemplar como aquele de Simone Cinotto (2001) relativo à "Cibo ed etnicità nella comunità italoamericana di New York' (Comida e etnicidade na comunidade ítalo-americana de Nova York), embora a análise seja concentrada sobre o período posterior, ou seja, os anos 20 e 30 do século XX, podem-se estabelecer relações comparativas com o caso extraordinário de São Paulo no final das últimas décadas do século XIX.

Com efeito, o Estado de São Paulo, e ainda mais a sua capital, ofereciam aos produtos italianos um mercado de consumo bastante favorável. As estatísticas de 1906 indicavam que, sobre uma população de cerca de quatro milhões de habitantes, aproximadamente, um quarto era de italianos ou de filhos de italianos, sem levar em conta que a mesma população brasileira estava cada vez mais se habituando ao consumo dos gêneros exclusivamente italianos, como vinho e azeite. Os números apontavam naquele ano uma importação de mercadorias alimentares da península que no Estado alcançava quase 0s 60\% de toda a importação italiana no Brasil (IL BRASILE; GLI ITALIANI, 1906).

A capital paulista, hoje considerada a primeira cidade no mundo em número de descendentes italianos, não ficou historicamente atrás de Nova York em termos de difusão de bairros étnicos, verdadeiras little italies, ou melhor, "pequenas itálias", no seu coração urbano, que graças à emigração europeia conheceu um desenvolvimento e uma expansão frenética nos anos analisados (TRENTO, 1998).

Contudo, o comércio dos produtos típicos adquiriu uma certa força mesmo nas outras cidades paulistas e do Sul de Minas, inseridas na economia do café, além do Rio de Janeiro e da capital rio-grandense, Porto Alegre, assim como em outros centros menores e periféricos do Estado mais meridional. São Paulo destacava-se amplamente, seja pelo número crescente de italianos que a escolheram como moradia, seja pelo fato que as escassas indústrias agrícolas ali presentes no final do século conectavam-se quase exclusivamente às lavouras do café, do açúcar ou do algodão. Os comerciantes italianos encontravam, assim, um ambiente propício para comercializar com maior facilidade vinhos, queijos e azeites característicos da península, que tinham uma grande reputação pela qualidade e genuinidade. Após a primeira tentativa falida em 1893, 
entre fevereiro e maio de 1902 foi fundada na capital paulista uma Câmara de Comércio Ítalo-Brasileira pela iniciativa de um grupo de banqueiros e empreendedores italianos ativos na capital do café, aos quais se agregaram outros imigrantes de Minas Gerais e do Rio Grande do Sul. O objetivo da instituição foi de "revigorar as relações da colônia com a pátria-mãe aumentando as transações recíprocas", conforme o Statuto della Camera di Commercio Italo-Brasiliana (FANFULLA, 17 mar. 1902) e de aglutinar os interesses econômicos dos italianos que - como destacou muitas vezes Emilio Franzina (2000, p. 74-77) -, nos primeiros anos do século XX reforçaram um "empreendedorismo étnico", sobretudo nos setores mercadológicos a baixo investimento de capital, como a venda dos gêneros alimentícios de importação.

Desde os anos precedentes, graças a poucos promotores neste setor, estabeleceu-se entre a Itália e o Brasil uma corrente de negócios, favorecida, ao menos no começo, pelo baixo custo dos artigos e pela situação favorável do câmbio. Tal processo foi ulteriormente incrementado com o emprego de caixeiros viajantes a serviço das principais casas comerciais italianas que, denominados "mascates", enfrentavam as dificuldades dos transportes para estender a rede dos produtos italianos mesmo na direção das fazendas e das colônias agrícolas no interior do Estado. Ampliou-se, assim, rapidamente, a rede das transações comerciais, também graças àqueles representantes, os "cometas", que viajavam continuamente de um lado a outro do oceano para manter vivas essas relações transnacionais ${ }^{5}$.

Muitos dos grandes industriais ítalo-paulistas começaram as suas parábolas econômicas ascendentes a partir do comércio de importação de produtos genuinamente italianos. Um exemplo é aquele de Giuseppe Martinelli que, antes de se tornar o grande industrial, construtor e armador que foi, iniciou com o pequeno comércio em São Paulo para trabalhar, posteriormente, em uma "casa de despachos" que no porto de Santos efetuava operações alfandegárias. Em pouco tempo, tornou-se proprietário da Casa (sucessivamente denominada "Fratelli Martinelli") à qual se anexou rapidamente uma seção bancária. A empresa adquiriu cada vez mais crédito, transformando-se em pouco tempo em representante oficial de importantes casas exportadoras italianas. O produto mais comercializado era o renomado licor "Fernet Branca", importado com sucesso de difusão, não apenas entre a comunidade italiana, mas também entre os brasileiros, através de uma perspicaz operação de marketing, "impondo-o com uma inteligente, hábil e bem organizada propaganda" sobre todos os principais jornais do Estado paulista (IL BRASILE; GLI ITALIANI, 1906, p. 1.002).

\footnotetext{
${ }^{5}$ Um dos casos mais exemplares é seguramente aquele de Narciso Gemignani, um imigrante de Viareggio definido o "príncipe dos viajantes" que desde o final do oitocentos até o ano de 1903, cruzou pelo menos 21 vezes o oceano entre Itália e Brasil. Veja-se: "Fanfulla", 1 out. 1898; e "Fanfulla", 27 fev. 1903.
} 
O mesmo modelo fora empreendido pelos irmãos Fiaccadori que, originários de Luzzara em Emilia, possuíam filiais em São Paulo, Nova York e Buenos Aires, especializadas no comércio do parmigiano reggiano e de lambrusco modenese (IL BRASILE E GLI ITALIANI, 1906, p. 1.004). Da mesma forma, Luigi Matarazzo, da célebre família ítalo-paulista originária da Campania, possuía vastos magazines e importava da Itália licores e vinhos (IL BRASILE E GLI ITALIANI, 1906, p. 1012). Um dos pioneiros em absoluto foi Eusebio Gamba que iniciou uma atividade de importação de produtos italianos em São Paulo já em 1876, deixando como herança para seus filhos um discreto patrimônio que permitiu a expansão da empresa nos anos subsequentes (IL BRASILE; GLI ITALIANI, 1906, p. 1017). Outra casa italiana de importação, a "A. Pagano e Comp." comprou a casa fundada em 1885 por Angelo Andreotti e se fez conhecer pela importação da Itália do vinho chinato e do vermouth Martinazzi; assim como a célebre empresa da família siciliana "Puglisi Carbone" possuía os seus depósitos gerais ao longo da ferrovia "São Paulo Railway", na recente infraestrutura que a partir do final do século XIX facilitava notavelmente os transportes dos produtos até o interior do Estado (IL BRASILE; GLI ITALIANI, 1906, p. 1020-1021). Também os irmãos Secchi, célebres pela grande fábrica de massas que abriram no princípio do século passado, além das máquinas pela produção, importavam da Itália o "Lambrusco de Sorbara", típico da sua região de origem (IL BRASILE; GLI ITALIANI, 1906, p. 1057-1058). Outro importante empreendedor no setor foi Ernesto Cocito que, no início dos anos 1900, abriu o Grand Hotel Roma na Estação da Luz de São Paulo, com magazines anexos em torno do terreno, onde mantinha a sua atividade de importação direta de "vinhos de luxo, de alimentos, azeites de oliva, licores, queijos, conservas e frutas". Com uma filial em Gênova, Cocito importava diretamente o vinho do seu estabelecimento de Castagnola no Piemonte com grandes expedições de garrafas bordolesi de Barbera, assim como de Vermouth (IL BRASILE; GLI ITALIANI, 1906, p. 1050-1051). Muitos licores italianos foram lançados nestes anos com enormes operações de propaganda no mercado brasileiro: um siciliano, Ignazio Tagliavia de Palermo, obteve, graças a amizade direta com o proprietário, a exclusividade de venda do renomado "Marsala Florio", e em seguida de tantos outros destilados da península; a "Casa Picosse" de São Paulo se orgulhava de ter lançado o "Amaro Montenegro" em todo o Estado paulista; a "Casa Acquarone", por outro lado, importava o "Amaro Felsina Ramazzotti" e o "Citrato Bertarelli", além de muitos outros vinhos das várias regiões italianas. Os casos encontrados são frequentes, até mesmo porque a estas empresas maiores se juntaram também as iniciativas de indivíduos provenientes principalmente das províncias meridionais de Salerno e Avellino, alguns dos quais se empregaram inicialmente nas indústrias Matarazzo para depois se emancipar com atividade de importação de alimentos.

São muitíssimos, em suma, os exemplos de italianos que se instalaram na cidade com este tipo de atividade - como demonstram os almanaques comerciais e as páginas dos jornais da época, que bombardeavam 
os leitores com publicidade relativa a tais exercícios -, tanto que seria impossivel elencá-los todos. A mesma coisa acontecia também nas localidades menores mais periféricas quando, com a expansão da fronteira do café, encheram-se de imigrantes italianos nos anos mais intensos dos fluxos.

Um instrumento excepcional para compreender o desenvolvimento de tal fenômeno é a imprensa étnica italiana que, financiada quase sempre pelos mesmos comerciantes, no Brasil teve uma proliferação enorme, sobretudo nos grandes centros urbanos (TRENTO, 2011). Através das páginas do "Fanfulla", por exemplo, exaltava-se a genuinidade e a autêntica proveniência "italiana", ou mais em geral, das várias regiões da península; publicavam-se as ofertas relativas à venda dos vinhos Chianti, Barolo ou Barbera; do azeite de Lucca; dos queijos "pecorini", mas também produtos regionais mais procurados e específicos como as castanhas do Apeninos, o panforte de Siena e os necci da Garfagnana. Às vezes, o mesmo jornal "impunha" aos bons italianos - com uma linguagem quase "intimidatória" -, o consumo de alimentos e produtos "nostrani" (da nossa terra natal), não apenas porque considerados melhores e genuínos, mas também porque úteis para fortalecer um sentimento identitário étnico. Em um dos tantos anúncios direcionados para a comunidade dos toscanos na cidade de São Paulo, leia-se: "qualquer bom filho da Etrúria deve ter em sua mesa um panforte de Siena para se lembrar da pátria distante"6.

Um papel seguramente especial neste setor era ocupado pelos toscanos, e mais exatamente pelos /ucchesi que, graças a uma emigração precoce de vanguardas, criaram há tempo alguns enclaves comerciais sustentados por robustas redes de relações e de proteção. Redes sociais consolidadas há muitos anos, permitiram a formação de verdadeiros "circuitos empreendedores", que no caso específico encontraram uma expressão tangivel nas principais cidades brasileiras envolvidas no fenômeno migratório italiano no final dos anos 1800. Também os dados recolhidos por Salvatore Pisani (1937, p. 1047) relativamente à cidade de São Paulo nos anos 30 do século XX demonstram que os toscanos ocupavam a maior parte do setor do "comércio de importação" e "dos negócios em geral". Alguns deles começaram com modestas iniciativas comerciais de importação alimentar para empreender, em seguida, a atividade de pequenos industriais com a abertura de moinhos, fábricas de massas, fábricas de cervejas etc.

Com este propósito, as inserções publicitárias dos principais jornais italianos no Brasil, mas também os almanaques comerciais ricos de imagens e fotografias e os mesmos depoimentos epistolares

6 Propaganda da "Confetteria São Bento" (das familias Accasto e Lazzarone) repetida mais vezes no mês de dezembro de 1898 em "Fanfulla". 
dos imigrantes, permitem definir melhor aquela que devia ser a atmosfera que se respirava entre os comerciantes italianos nas vias centrais das principais cidades. Entre os vários exercícios deste tipo, no final do século XIX, em São Paulo, destaca-se, por exemplo, a "Brasserie Paulista" que, apesar do francesismo, era considerada o "templo sagrado da gastronomia", sobretudo italiana, local importante de encontro da elite paulistana e, ao mesmo tempo, um lugar simbólico da sociabilidade internacional e multicultural presente na cidade. O proprietário, junto com Vittorio Fasano, era o fiorentino Ugo Fazzini que, dono de vinhedos na sua região, importava diretamente fiaschie garrafas de vinho Chianti, junto com os embutidos, queijos e produtos típicos toscanos. No local podiam-se degustar também a mortadela de Bolonha, os zamponi de Modena e o cotechino, além do queijo parmesão e o gorgonzola (IL BRASILE; GLI ITALIANI, 1906, p. 1067-1068).

Nos mesmos anos despontavam também os filhos de Francesco Bertolli, o fundador da família ainda hoje dedicada à atividade no setor agroalimentar, que em 1875 abriu em Lucca uma agência de câmbio exclusivamente dedicada às operações de troca de moedas e empréstimos de dinheiro para quem tinha intenção de partir para os longínquos países transoceânicos. Ao mesmo tempo, dedicava-se à compra de alimentos em atacados para revendê-los no varejo. Buscava normalmente produtos da agricultura regional como queijo, azeite e vinho. Muitos entre os emigrantes que utilizavam a agência bancária de Bertolli tornavam-se, no exterior, verdadeiros agentes de comércio dedicados às tratativas pelas importações dos deliciosos produtos locais. Em São Paulo, em 1898, o filho de Francesco, Giuseppe Bertolli, abriu uma sociedade composta por outros compatriotas, que se ocupava especificamente de importar os desejados produtos alimentares italianos não apenas no Brasil, mas também nos Estados Unidos e no Transvaal (OSTUNI, 2016, p. 16). Poucos anos depois, a empresa Bertolli se fundiu em São Paulo com a "Andreotti", outra sociedade lucchese especializada no comércio de atacado de gêneros alimentícios italianos, e rapidamente os seus representantes alcançariam também a cidade mais meridional de Porto Alegre, capital do Rio Grande do Sul, o segundo Estado brasileiro numericamente mais envolvido na imigração italiana (CINQUANT'ANNI DI LAVORO DEGLI ITALIANI IN BRASILE, 1937). Lucchesi eram também os sócios Luigi Favilla e Domenico Lombardi, que possuíam depósitos permanentes de trigo e importavam diretamente gêneros italianos e, sobretudo, toscanos ${ }^{7}$. 0 mesmo podia-se dizer a respeito de Domenico Barsotti, lucchese que em 1889 abriu em São Paulo a confeitaria "Al vino Chianti", que além da importação de produtos italianos, possuía um espaço recreativo com bilhar e mesas de jogos de cartas

${ }^{7}$ Veja-se as numerosas inserções publicitárias em: Almanacco del "Fanfulla", São Paulo, 1903. 
(ALMANACCO ILLUSTRATO DELLA "TRIBUNA ITALIANA", 1905). Muitos outros são os nomes de toscanos que se encontram através da leitura de artigos de propaganda comercial no "Fanfulla", o mais famoso quotidiano étnico da comunidade italiana: "Nesti e Guastini", que importavam vinhos e licores italianos além do prestigiado azeite de Lucca; "Gustavo Lenci e Figlio", exportador de vinhos "de mesa e de luxo", entre os quais o renomado Chianti Cinquini, mas também Chianti em barris e em "fiaschi toscanos de dois litros", junto com o queijo pecorino da Garfagnana e dos presuntos e embutidos italianos; "Falchi Giannini e Cia.", importadores de gêneros alimentícios, depositários do Chianti" Busoni" e das "maravilhosas Águas das Regias termas de Montecatini"; "Pieri e Belli", que representavam desde 1890 a empresa Bertolli de Lucca; Galileo Nieri, que trazia o Chianti Ruffino; "Fratelli Cinquini", importadores de vinho, queijos e óleos da Toscana; "Fratelli Bonciani", de Castelfiorentino, que introduziam o próprio Chiantialém do vinho aleatico; "Francesco Papini", reconhecido como um "toscano puro-sangue", que importava e revendia em atacado produtos típicos regionais, além do vinho Chianti"Ernesto Mori"; assim como os "Fratelli Gangini", especializados na importação de vinho e azeite e o senhor "Cavallini", que comercializava em São Paulo o vinho de Carmignano ${ }^{8}$.

Emblemática aparecia a história de um enviado do "Fanfulla", que na coluna jornalística intitulada "Da S. Paulo a S. Paulo", em 4 maio de 1899, percorria as vias do centro da cidade para individualizar e descrever as principais atividades desenvolvidas pelos imigrantes italianos:

Quatro passos à frente uma outra fiaschetteria (enoteca) muito conhecida e apreciada: quero falar daquela dos senhores Pietro e Emanuele, irmãos Bonciani, que graças a um longo período de permanência na praça e à deliciosa qualidade dos vinhos importados das suas renomadas vinícolas de Castel Fiorentino, soube adquirir invejável fama, não apenas na cidade, mas em todo o Estado. A clientela dos senhores Bonciani está entre as melhores e o seu Chianti mantém elevado o prestígio da indústria vinícola italiana. Após ter visitado duas fiaschetterie é prudente mudar de ambiente, até porque na última das duas se encontrou um vin santo que traria facilmente os santos da estrada certa; e um Alkermes fiorentino delicioso, feito para as senhoras gentis, mas consumido também pelos senhores grosseiros. Caminhando na Rua Boa Vista encontra-se a fiaschetteria de Guido Puccinelli, conhecido desde quando no mesmo ponto o pai exercitava o mesmo comércio enquanto o filho deliciava-se com a maldade inócua. [...] No mesmo negócio não faltavam os licores finos e as petisqueiras, que em bom toscano chamam-se de spuntini, e não falta jamais a boa acolhida e a simpatia do proprietário, e a alegre brigada dos jovens que asseguram à casa um próspero futuro (FANFULLA, 4 mai. 1899).

${ }^{8}$ Nomes e noticias foram levantados através da leitura do "Fanfulla" de 1898 a 1900. 
Recantos de comida italiana nessa mesma rua eram também o "Caffè del Serchio", um elegante bar aberto pela senhora Emma Ballerini, onde havia sempre "à disposição chop fresquíssimo, licores finíssimos e vinhos genuinamente importados das melhores cantinas toscanas", e o restaurante italianíssimo " $\mathrm{La}$ Giardiniera", aberto pelo fiorentino Francesco Regoli.

Também no Rio Grande do Sul não faltaram, de fato, alguns casos de estudos interessantes entretanto muitas vezes ofuscados, por causa da atenção quase exclusiva que as pesquisas dirigiram para a preponderante imigração agrícola nas colônias -, tanto na capital como no interior do Estado, nas localidades aparentemente periféricas e isoladas. Em Porto Alegre não se podia ignorar a discreta quantidade de pequenos comerciantes italianos, entre os quais lucchesi, romagnoli e meridionais das províncias de Salerno, Avellino, Potenza e Cosenza (CONSTANTINO, 2015). Muitos se dedicaram à venda de gêneros alimentícios, frequentemente de importação italiana, que se associava àquela colonial, e nos principais bairros com forte presença italiana não faltavam os restaurantes e bares de imigrantes da península. Angelo Pellegrini nas páginas do jornal italiano "Pasquino", nos primeiros anos do século passado, patrocinava os "deliciosos funghi frescos" da Garfagnana, importados diretamente por uma empresa de Lucca e vendidos no seu magazine na cidade? .

Exemplos interessantes de promoção e venda do made in Italy enogastronômico se repetiam também nas cidades portuárias principais como Rio Grande e Pelotas, na extremidade mais meridional do país, ou seja, duas das cidades mais cosmopolitas do Estado, considerada também a sua posição geográfica de fronteira com o Uruguai. 0 que mais surpreende, porém, era aquilo que ocorria nas pequenas cidades mais internas ou de fronteira, onde desde a metade do século XIX existia uma intensa mobilidade humana de europeus e, sobretudo, de italianos provenientes também dos países vizinhos. Nestas localidades os italianos não perderam a ocasião de inserir-se no comércio de gêneros alimentícios importados, tanto das colônias agrícolas do Estado como diretamente da península (DE RUGGIERO, 2015). Um exemplo, seguramente emblemático, é o dos irmãos Emanuele Filiberto e Vincenzo Luisi, provenientes de Torraca, na província de Salerno, que em Cruz Alta, um pequeno centro urbano não muito distante da fronteira argentina, utilizado frequentemente como emblema do modelo de vida gaúcho, no começo do século XX fundaram uma grande casa comercial onde, além dos produtos da colônia, se encontravam:

\footnotetext{
${ }^{9}$ Apesar das várias lacunas e a escassa organização dos exemplares até hoje presentes no Arquivo do "Museu da Comunicação Hipólito José da Costa" de Porto Alegre, notícias deste tipo encontra-se graças as inserções publicitárias de alguns periódicos ou cotidianos da comunidade italiana no Rio Grande do Sul.
} 
Azeites de Genova, da Toscana e das Puglie; conservas de tomates de Parma e de Nápoles; conservas alimentares de todos os gêneros e tudo o quanto de melhor que se poderia encontrar na Itália. E a sua iniciativa não para por aqui [...] Importam da Itália sementes de hortaliças e de flores e brotos de vinhas muito procurados e que até agora deram resultados surpreendentes (CINQUANTENARIO DELLA COLONIZZAZIONE ITALIANA NEL RIO GRANDE DEL SUD, 2000, p. 249, v. 2).

Um recanto da Itália e das suas comidas deliciosas, em suma, no coração do Pampa, que nos diz muito a respeito da importância histórica dessa penetração cultural no mundo.

\section{CONSIDERAÇÕES FINAIS}

Como escreveu o antropólogo italiano Ernesto Di Renzo, em todos os processos migratórios a comida assume um papel de "catalisador de lembranças", oferecendo aos protagonistas dessas mobilidades humanas, a possibilidade de abater as barreiras espaço-temporais e reconectar-se com os lugares e os afetos de origem (DI RENZO, 2015, p. 406). 0 interesse emotivo de milhares de imigrantes localizados mentalmente entre dois espaços (o de partida e o de chegada) se tornou, também no caso brasileiro, o estímulo principal para a proliferação de empreendimentos comerciais étnicos que garantiram em um primeiro momento a possível manutenção dos costumes alimentares originários.

Inicialmente percebida como uma forma de resistência cultural e de defesa das tradições mais íntimas, ao longo dos anos a gastronomia italiana contribuiu, ao mesmo tempo, para fomentar processos de integração e interação, construindo novas identidades culinárias transnacionais, na sua fusão com as diversas culturas gastronômicas de um país multiétnico como o Brasil.

\section{REFERÊNCIAS}

ALMANACCO ILLUSTRATO DELLA "TRIBUNA ITALIANA". San Paolo, 1905.

BEVILACQUA, Piero. Emigrazione transoceanica e mutamenti dell'alimentazione contadina calabrese fra Otto e Novecento. Quaderni Storici, n. 47, 1981. 
BIANCO, Francesco. II Paese dell'avvenire. Milano-Roma: A. Mondadori, 1922.

CAFFARENA, Fabio. II viaggio dei sapori: Il cibo nelle lettere degli emigranti in America, 2006. Disponível em: <http://www.pellegrino artusi.it/convegni-artusiani-2/2006-2/>. Acesso em: 20 set. 2015.

CINOTTO, Simone. Una famiglia che mangia insieme: Cibo ed etnicità nella comunità italoamericana di New York, 1920-1940. Torino: Otto Editore, 2001.

CINQUANT'ANNI DI LAVORO DEGLI ITALIANI IN BRASILE. San Paolo: Societá Editrice Italiana, 1937.

CINQUANTENARIO DELLA COLONIZZAZIONE ITALIANA NEL RIO GRANDE DEL SUD: 1875-1925. 2. ed. Porto Alegre: Posenato Arte \& Cultura, 2000.

CONSTANTINO, Núncia Santoro de. L'italiano di Porto Alegre: immigrati meridionali nella capitale del Rio Grande do Sul. Cosenza: Pellegrini, 2015.

CORTI, Paola. Emigrazione e consuetudini alimentari. L'esperienza di una catena migratoria. In: CAPATTI, Alberto; DE BERNARDI, Alberto; VARNI, Angelo (a cura di). Storia d'Italia: Annali 13: L'alimentazione. Torino: Einaudi, 1998.

CRISTALDI, Flavia. E andarono per mar a piantar vigneti: gli Italiani nel Rio Grande do Sul. Todi (PG): Tau, 2015.

DALL'OGLIO, Maria Attilia Fabbri. I sapori perduti: itinerario gastronomico europeo dal XIV secolo alla Belle époque. La storia, le ricette, Roma: Garamond, 1993.

DE AMICIS, Edmondo. Em alto-mar. São Paulo: Nova Alexandria, 2017.

DE RUGGIERO, Antonio. Os italianos nos contextos urbanos do Rio Grande do Sul: perspectivas de pesquisa. In: VENDRAME, Maíra Inês; KARSBURG, Alexandre; WEBER, Beatriz; FARINATTI, Luiz Augusto (Org.). Micro-história, trajetórias e imigração. São Leopoldo: OIKOS, p. 162-181, 2015.

DI RENZO, Ernesto. Cibo, identità, migrazione: alcune reflessione a margine dell'emigrazione italiana nel mondo. Disponivel em: <https://www.academia.edu/8686237/Cibo_identità_migrazione_alcune_ riflessioni_a_margine_dellemigrazione_italiana_nel_mondo>. Acesso em: 20 dez. 2015.

FANFULLA: II Giornale Degli Italiani in Brasile dal 1893. São Paulo, 1898-1903. 
FIGUEIREDO, Franciele Bandeira. Gastronomia e hibridismo cultural de restaurantes italianos em Gramado (RS) - Estudo de Caso. Cultur: Revista de Cultura e Turismo, v. 3, p. 112-123, 2009.

FRAGMENTOS DA PRESENÇA ITALIANA NO BRASIL: 100 ANOS. São Paulo: Câmara Ítalo-Brasileira de Comércio e Indústria, 2002.

FRANCESCHINI, Antonio. L'emigrazione italiana nell'America del Sud. Roma: Forzani e C., 1908.

FRANZINA, Emilio. Le comunità imprenditoriali italiane e le Camere di Commercio all'estero (18701945). In: SAPELLI, Giulio (a cura di). Tra identità culturale e sviluppo di reti: storia delle Camere di commercio italiane all'estero. Soveria Manelli: Rubbettino, 2000. p. 65-85.

. Merica! Merica!: emigrazione e colonizzazione nelle lettere dei contadini veneti in America Latina (1876-1902). Milano: Feltrinelli, 1979.

IL BRASILE E GLI ITALIANI: pubblicazione del Fanfulla. Firenze: Bemporad, 1906.

MARCATO, Carla. Parole migranti nel lessico dell'alimentazione. Rivista Oltreoceano, Udine, n. 4, p. 1926, 2010.

ORTOLEVA, Peppino. La tradizione e l'abbondanza. Riflessioni sulla cucina degli italiani d'America.

Rivista Altreitalie, Torino, n. 7, 1992.

OSTUNI, Maria Rosaria. Storia/storie dell'emigrazione toscana nel mondo. Lucca: Fondazione Paolo Cresci, 2006.

PECCINI, Rosana. A invenção da galeteria: o galeto al primo canto e o patrimônio de cultural de Caxias do Sul. Caxias do Sul: Editora da Universidade de Caxias do Sul, 2011.

PELLANDA, Ernesto. Aspectos gerais da colonização italiana no Rio Grande do Sul. In: Álbum comemorativo do $75^{\circ}$ aniversário da colonização italiana no Rio Grande do Sul. Porto Alegre: Globo, 1950. p. 34-64.

PISANI, Salvatore. Lo Stato di San Paolo nel Cinquantenario dell'Immigrazione. São Paulo: Typographya Napoli, 1937.

SANTOS, Miriam Oliveira; ZANINI, Maria Catarina. Comida e simbolismo entre imigrantes italianos no Rio Grande do Sul (Brasil). Caderno Espaço Feminino, Uberlândia, MG, v. 19, n. 01, p. 255-285. jan./jul. 2008. 
TETI, Vito. Emigrazione, alimentazione, culture popolari. In: BEVILACQUA, Piero; DE CLEMENTI, Andreina; FRANZINA, Emilio (a cura di). Storia dell'emigrazione italiana: Arrivi. Roma: Donzelli, p. 575$597,2001$.

TRENTO, Angelo. La costruzione di un'identità collettiva: storia del giornalismo in lingua italiana in Brasile. Viterbo: Sette Città, 2011.

. L'immagine di São Paulo come città italiana (1890-1920). In: GIORCELLI, Cristina; CATTARULLA, Camilla; SCACCHI, Anna (a cura di). Città reali e immaginarie del continente americano. Roma: Editrice Associate, 1998.

VERNASSA, Maurizio. Alle origini dell'interessamento italiano per l'America Latina: modernizzazione e colonialismo nella politica crispina: I'inchiesta del 1888 sull'emigrazione. Pisa: ETS, 1996. 